\title{
Turizm Şûraları Protokol Konuşmalarının Kalkınma Planları Kapsamında Değerlendirilmesi
}

\author{
DOI: $10.26466 /$ opus.554732
}

*

\section{Gencay Saatc1*}

* Dr. Öğr. Üyesi, Çanakkale Onsekiz Mart Üniversitesi, Turizm Fakültesi / Çanakkale / Türkiye E-Posta: gencaysaatci@comu.edu.tr

ORCID: 0000-0002-7842-989X

\section{Öz}

Yapılan bu çalışmanın amacı ilki 1998, ikincisi 2002 ve üçüncüsü de 2017 yıllarında düzenlenmiş olan Turizm Şûralarındaki protokol konuşmalarının, 1963-2018 yılları arasında yayımlanan Türkiye'nin on adet beş yıllık kalkınma planları kapsamında incelenmesidir. Çalışmada nitel araştırma yöntemlerinden içerik analizi yöntemi kullanılmıştır. Verilerin analizi aşamasında turizm şûraları protokol konuşmaları metin haline getirilip incelenmiş ve inceleme sonucunda değinilen konular kategorize edilerek kalkınma planları altında toplanarak kodlanmıştır. Toplam 10 adet tema belirlenmiş ve bu temalara ilişkin 76 adet alt kategori oluşturulmuştur. Elde edilen bulgular genel olarak değerlendirildiğinde; 7. Beş Yillık Kalkınma Planı hakkında en çok konuşulan kalkınma planı olmuştur. "Alternatif Turizm" teması 3 şûrada da gündeme gelmiştir. Bu temayı sırasıyla; dış turizm gelirleri, marka oluşturma, tanıtım faaliyetleri, alt yapt ile doğal ve kültürel değerler temalar izlemektedir. Araştırma sonucunda ise; kalkınma planlarında ele alınmayıp protokol konuşmalarında üzerinde durulan; hijyen, insan sağlığ̆, güven ortamı, insan hakları ve kültürlerarası yakınlaşma temaları ortaya çıkmıştır.

Anahtar Kelimeler: Kalkınma planı, Turizm şûrası, Protokol konuşmaları, İçerik analizi 
ISSN:2528-9527

E-ISSN : 2528-9535

YIl Year: 9

Cilt Volume: 11

Sayı Issue : 18

Uluslararası Toplum Araştırmaları Dergisi International Journal of Society Researches

Haziran June 2019 Makalenin Geliş Tarihi Received Date: 16/04/2019 Makalenin Kabul Tarihi Accepted Date: 15/05/2019

\title{
An Evaluation of The Protocol Speeches Given at The Tourism Councils in The Scope of Development Plans
}

\begin{abstract}
The aim of study is to evaluate the protocol speeches given at the Tourism councils, which was held in 1998, 2002 and 2017, within the scope of Turkey's ten 5-Year development plans issued between 1963 and 2018. In the analysis of the data, protocol speeches were transcribed and analyzed, then, the themes emerged at the end of the analyses were categorized and coded accordingly. A total of 10 themes were identified and 76 sub-categories were created. When the findings are evaluated in general; the 7 th 5Year Development Plan has emerged as the plan which was mentioned about the most. The theme "Alternative Tourism" has come up at the 3rd council as well. The study found that the themes of hygiene, human health, trust environment, human rights and intercultural rapprochement have emerged as the issues that were not addressed in the development plans, yet mentioned about in the protocol speeches.
\end{abstract}

Keywords: Development plan, Tourism council, Protocol speeches, Content analysis 


\section{Giriş}

Ülkemizde Devlet Planlama Teşkilatı (DPT), tarafından hazırlanan Beş Yıllık Kalkınma Planları, Türkiye'nin mevcut ekonomik, sosyal ve kültürel alanlarda, uzun dönemde gerçekleştireceği büyümeyi ortaya koyan temel politika dokümanlarıdır. 1963 yılından itibaren 2018 yılını da kapsayacak biçimde on tane kalkınma planı hazırlanmıştır ve ulaşılmak istenen hedefler ile ulaşılmak istenen yapı ele alınmıştır (Tüzünkan, 2015; Akça, Şahan ve Tural, 2017). Söz konusu beş yıllık kalkınma planlarında turizm olgusuna bakıldığında; başlangıçta, kalkınma planlarında turizm bir ekonomik aktivite olarak görülmüştür. Kısa vadede turizm hareketlerini ve ekonomik faydalarını arttırmak, turizm endüstrisinin hızla gelişmesini sağlamak için ilgili tedbirlerin alınması amaçlanmıştır. İlk dönemde büyük oranda kitle turizmi odaklı yapılan seyahatler hedeflenirken; daha sonraki turizm planlarında talebin coğrafi dağılımını sağlamak, mevsimselliği azaltmak için, katma değeri daha yüksek olan alternatif turizm çeşitleri ekseninde turistik ürünün çeşitlendirilmesi ve her mevsimde turizm olanaklarından yeterince yararlanabilmek üzerinde durulmaktadır. Bununla birlikte yerel halkın da yatırımlara katılabildiği daha küçük turizm işletmeleri özendirilmiştir (Dinçer ve Çetin, 2015; Keleş ve Akbaş, 2016). Turizmin ekonomik kalkınmadaki önemi her hükümet tarafından takdir edilmiş ve bu bakış açısı Devlet Planlama Teşkilatı'nın hazırladığı beş yıllık kalkınma planlarına da farklı düzeylerde yansımıştır (Ünlüönen, Tayfun ve Kılıçlar, 2007).

Türk turizm tarihinde önemli bir yer tutan Turizm Şuraları ise turizm sektöründeki sorunların kapsamlı şekilde ele alınması, turizmin sorunlarına uzun vadeli bir anlayışla yaklaşılması, turizmi geliştirici, ileriye dönük, kalıcı politikalar oluşturulması ve kararlı adımlar atılması konusunda sektörün taraflarını bir araya getiren en önemli platformlardan biri olma özelliği taşımaktadır.

\section{Alanyazın}

Kalkınma kavramı, ilk olarak batı Avrupa ülkelerinde ortaya çıkmış ve daha sonrasında diğer ülkeleri de içine alan önemli bir konu haline 
gelmiştir. Kalkınma konusunda, zamanla insan odaklı bir anlayış benimsenmiş ve kalkınma; bir bütün olarak hem ekonomik hem toplumsal açıdan çok yönlü bir anlama bürünmüştür (Yemen, 2015, s.1002). Kalkınma planları ekonomi politikasının hedefleri ve bu hedeflere ulaşmak için görev, yetki ve araçları belirlemek için yapılan kamu için emredici, özel sektör için ise teşvik edici unsurlar içeren, mecliste kabul edilen kanunlar niteliğindedir. Beş yıllık kalkınma planları süreleri gereği orta vadeli planlar arasında sayılan dönemsel planlama türlerindendir (Dinçer ve Çetin, 2015).

Kalkınma planlarının Türkiye'ye yansıması, 1960'lı yılları bulmuştur. Türkiye'deki ekonomik ve toplumsal gelişmeyi arttırmak adına bölgesel eşitsizlikleri azaltmak, toplumsal ve ekonomik dengeyi sağlamak amacıyla, planlı kalkınma anlayışıyla beş yıllık kalkınma planları oluşturulmuştur (Yemen, 2015). Türkiye'de turizmin gelişimi ve turizm politikalarının evrimini dönemsel olarak ele alan çalışmalara bakıldığında genellikle Planlı Dönem Öncesi ve Planlı Dönem şeklinde iki ana sinıflandırmanın yapıldığı görülmektedir. Planlı Dönem Öncesinde alt dönemler; 1923-1930 1931-1939, 1940-1949 ve 1950-1960 olarak belirlenmekte, 1960 yılından sonraki dönem ise Planlı Dönem olarak kabul edilmektedir (Olalı ve Timur, 1988; Barutçugil, 1986; Çeken, 2003; Kozak vd, 2009; Uçar vd, 2010; Soyak, 2013).

Türkiye'de turizmin ekonomik, sosyal ve kültürel etkileri 1940'lardan sonra fark edilmiş, 1963 yılından 1980'li yıllara kadar, zamanla gelişme eğilimi göstermiştir. Planlı dönem öncesi (1923-1963) Türkiye'de turizm oldukça yavaş bir ilerleme göstermiştir ve bu dönemle ilgili geniş verilere ulaşmak pek mümkün değildir. Türkiye'nin planlı dönem öncesinde karayolları, limanlar ve konaklama tesisleri yetersiz, turizmle ilgili çalışmalar son derece kısıtlıdır. 1929 dünya ekonomik buhranı, 1939'da başlayan ve altı yıl süren ikinci dünya savaşı turizm faaliyetlerini olumsuz yönde etkilemiştir. Türkiye'de 1950'li yıllarda başlayan imar faaliyetleri, altyapı ve üst yapı yatırımları ile tarihi eserlerin restorasyonu ileriki yıllarda ortaya çıkacak olan turizm sektörüne katkı sağlamıştır. Bu dönemdeki önemli gelişmelerden birini 1953 yılında yürürlüğe giren Turizm Endüstrisi Teşvik Kanunu oluşturmaktadır. Diğeri ise; 1957 yılında Turizm Bakanlığı'nın kurulmasıdır. Turizm esas gelişimini planlı dönemde (1936-2018) sağlamıştır. 1960 yılına kadar turizm sektörüne gereken önemi 
göstermemiş olan devlet, bu yıldan sonra düzenlenen ve uygulamaya başlanan gelişme politikası niteliğindeki beş yıllık kalkınma planlarında, turizmin geliştirilmesi için gerekli önlemlere yer vermiştir. Ancak 1961 Anayasası, planlı kalkınmayı hazırlayan gelişmeleri beraberinde getirmiştir. Diğer bir deyişle; destinasyon olarak Türkiye 1977-1987 yılları arasında başlangıç, 1987-1997 yılları arasında büyüme, 1998'ten itibaren ise olgunluk dönemine giriş sinyalleri vermeye başladığ 1 gözlemlenmektedir (Usta, 2014; Akça, 2016; Büyükşalvarc1 vd., 2016). 1963-2018 yılları arasında uygulanan beş yıllık kalkınma planlarında turizm ile ilgili incelenen başlıklar genel olarak şu şekilde özetlenebilmektedir (www.sbb.gov.tr, Erişim: 02.03.2019):

\section{Birinci Beş Yıllık Kalkınma Planı (1963-1967)}

Uluslararası reklam firmaları aracılığıyla Türkiye'nin tanıtımının yapılması. Bazı ülkelerde “Turist Eğilimleri Araştırması”nın yapılması. İç turizmin teşvik edilmesi. Turizm ile ilgili tüm işleri yürütecek bir teşkilat kurulması. Turizm gelişimini planlayacak "Turizmi Geliştirme Kurulu” nun kurulması. Turistlerin gümrük ve döviz işlemlerinin kolaylaştıracak önlemler alınması. Turizm danışma bürolarının açılması. Turizm Bankası'nın iyileştirilmesi ve uygun turistik tesislere kredi verilmesi. Turizmin gelişimini olumsuz etkileyen yasa ve hükümlerin değiştirilmesi. Festivaller ve olimpiyat düzenlenmesi için araştırma yapılması. Turizm personelinin eğitilmesi. Yeni yapılacak otellerin bir süreliğine bina vergisinden muaf tutulması. Kamu kesimine ait dinlenme kamplarından turistlerin faydalanması. Halk eğitim programları kapsamında turistik eserlerin tanıtılması. Bağımsız yiyecek-içecek ve hediyelik eşya satan işletmelerin desteklenmesi. Turistik olarak gelişime açık doğal güzelliklerin kullanılmasının teşvik edilmesi.

\section{İkinci Beş Yıllık Kalkınma Planı (1968-1972)}

Dış turizm gelirlerinin ve ortalama turist harcamalarının artırılması. İç turizmin geliştirilmesi. Turizm yatırımlarının turistik potansiyeli olan bölgelerde yoğunlaştırılması. Kitle turizminin teşvik edilmesi. Fiyat politikasının uluslararası rekabet şartlarına göre düzenlenmesi. Turizmin 
ekonomik, sosyal ve kültürel işlevlerinden yararlanılması. Teşkilatlanmanın, tanıtmanın ve kredi politikalarının yeniden düzenlenmesi. Alt yapı ve örnek tesislerin kamu; diğer yatırımların özel sektörce yapılması.

\section{Üçüncü Beş Yıllık Kalkınma Planı (1973-1977)}

Yatırımların ve tanitma faaliyetlerinin kitle turizmine entegre edilmesi. Özel sektör yatırımlarının ve özel sektör işletmeciliğinin teşvik edilmesi. Alt ve üst yapı yatırımlarında İmar ve İskân Bakanlı̆̆ı ile Turizm ve Tanıtma Bakanlığı'nın iş birliğinin sağlanması. Kıyıların toplum yararına kullanılması için mevzuat oluşturulması. Turizm yatırımları için genel bankaların da özendirici tedbirler alması. Sosyal turizmin gelişmesine önem verilmesi. İç turizmin teşvik edilmesi. Uygulamalı turizm eğitimine ağırlık verilmesi. Personelin yıl boyu istihdamının sağlanması.

\section{Dördüncü Beş Yıllık Kalkınma Planı (1979-1983)}

Kitle turizmine uygun sektör işleyişinin sağlanması. Yatırım ve işletmecilikte kamu sektörünün etkinliğinin artırılması. Konaklama kapasitesinin artırılması. Yabancı yatırımcıların işletmecilik yapmasının özendirilmesi. Yabancı uyruklu personel çalıştırılmasının kolaylaştırılması. Kamuya ait turistik tesislerin tek merkezden yönetilmesi. Kamuya ait turistik tesislerin dış turizme açılması. Kamuya ait turistik tesislerde iç turizme yönelik olarak kâr amacı güdülmemesi. Mevsim içi uçak filosunun artırılması amacıyla charter seferlerin düzenlenmesi. Personelin tatil gereksinimini karşılamak için gerekli önlemler alınması. Kıyıların kamu yararına kullanılmasının sağlanması. İkinci konut yapımının önlenmesi. Her turiste ülkede kalacağı gün için döviz bozdurma zorunluluğu getirilmesi. Ana güzergâhlar üzerinde servis çekirdeklerinin oluşturulması. Turizmin zamanda yoğunlaşmasının önlenmesi. Giriş kapılarında geçiş işlemlerinin kolaylaştırılması. Turizm eğitim politikasının ülke gereksinimini karşılayacak şekilde düzenlenmesi. Turizm istatistiklerinin geliştirilmesi. 


\section{Beşinci Beş Yıllık Kalkınma Planı (1985-1989)}

Balkan Ülkeleri ve Üçüncü Dünya Ülkeleri ile de ilişkilerin geliştirilmesi. Bireysel turizm ihmal edilmeden kitle turizminin özendirilmesi. Çalışanların tatil yapmalarının teşvik edilmesi. İstatistiki veri toplanmasında modern imkânlardan faydalanılması. İç turizm ile ilgili verilerin elde edilmesi. Turizm potansiyelinin ekolojik dengenin korunmasi kapsamında değerlendirilmesi. Doğal çevre ile kültürel çevrenin korunması ve geliştirilmesi. Turizm kaynakları envanteri çalışmalarında kurumlar arası iş birliği sağlanması. Turizm Bankasının yatırım yapmak yerine fonları kredi olarak kullandırması.

\section{Altıncı Beş Yıllık Kalkınma Planı (1990-1994)}

Hizmet verenlerin nitelik ve nicelik olarak geliştirilmesi. Alt ve üst yapının geliştirilmesi. Doğal ve kültürel çevrenin korunarak turizme açılması. Charter taşımacılığın geliştirilmesi. Alternatif turizm türleri için teşvik politikalarının geliştirilmesi. Tesislerin doluluklarının artırılması. Turizm mevsimini uzatıcı faaliyetlerin teşvik edilmesi. Aile işletmeciliğinin teşvik edilmesi. Toplumun tatil yapmasının sağlanması.

\section{Yedinci Beş Yıllık Kalkınma Planı (1996-2000)}

Yerel halkın ve turistlerin sektörden beklentilerinin karşılanması. Doğal ve kültürel değerlerin sürekliliklerinin sağlanması. Var olan üst yapının daha aktif kullanılması. Doğal sermayenin korunması. Yeni alternatif turizm çeşitlerinin geliştirilmesi. Yerel yönetimlerin ve yerel halkın turizm ile ilgili kararlara katılması. Fiziki planların amaca yönelik olarak uygulanması. Küçük ölçekli işletmelerin geliştirilmesi. Yerli tur operatörlerinin yaygınlaştırılması. Tanıtma ve pazarlama faaliyetleri için özel sektörün katılımının sağlanması. Alt ve üst yapının entegre olması için düzenlemeler yapılması. Akdeniz-Ege Turizm Altyapısı ve Kıyı Yönetimi (ATAK) projesinin uygulanması. Kamu tarafından yapılan alt yapı finansmanına kullanıcılarında dâhil edilmesi. Turizm Sektörü Ana Planı (TUSAP)'nın uygulamaya geçirilmesi. Sertifikasyon sistemine geçilmesi. 
İkinci konutların pazarlanmasına yönelik organizasyonların geliştirilmesi.

\section{Sekizinci Beş Yıllık Kalkınma Planı (2001-2005)}

Turizmin kendi kaynağını yaratabilen bir sektör olmasının sağlanması. Yeni alanlarda turizmin geliştirilmesi. Yatırımların doğal, tarihi ve sosyal çevreyi korumasının sağlanması. Pazarlamaya, hava ulaştırmasına ve toplam kaliteye öncelik verilmesi. Yerel yönetimlerin ve yerel halkın turizm ile ilgili kararlara katılması. Kamu tarafından yapılan alt yapı finansmanına kullanıcılarında dâhil edilmesi. Akdeniz-Ege Turizm Altyapısı ve Kıyı Yönetimi (ATAK) Projesi kapsamındaki projelerde hazine garantisine gerek duyulmayacak bir model oluşturulması. Küçük ölçekli işletmelerin geliştirilerek KOBİ olarak değerlendirilmeleri. Turizm eğitimi ve kalitesinde belgelendirme sisteminin oluşturulması. Turizme yönelik arazilerin kullanımının denetlenmesi için yasal düzenleme yapılması. Turizm Sektörü Ana Planı (TUSAP)'nın uygulamaya geçirilmesi. Dış pazarlarda Avrupa Birliği dışındaki ülkelere de yönlenmesi. Alternatif turizm faaliyetlerinin sürdürülmesi. Milli park alanlarında sürdürülebilir turizmin geliştirilmesi.

\section{Dokuzuncu Beş Yıllık Kalkınma Planı (2007-2013)}

Yeni yörelerde turizmin geliştirilmesi. Yatırımların doğal, tarihi ve sosyal çevreyi korumasının sağlanması. Turistik ürünün niteliğinin yükseltilmesinin sağlanması. Alternatif turizm faaliyetlerinin sürdürülmesi. Sağlık turizminin desteklenmesi. Turizm teşviklerinde pazarlamanın, hava ulaştırmasının ve toplam kalitenin iyileştirilmesi. Yerel yönetimlerin ve yerel halkın turizm ile ilgili kararlara katılması. Kamu tarafından yapılan alt yapı finansmanına kullanıcılarında dâhil edilmesi. Turizm Sektörü Ana Planı'nın hazırlanması. Turizm eğitimi ve kalitesinde belgelendirme sisteminin oluşturulması. 


\section{Onuncu Beş Yıllık Kalkınma Planı (2014-2018)}

Turizmde marka haline gelinmesinin sağlanması. Üst gelir grubuna hitap edecek şekilde turistik ürün çeşitlendirilmesi. Kalitenin artırılması ve sürdürülebilirlik ilkesi çerçevesinde bölgesel kalkınmada öncü bir sektör haline gelinmesi. Sağlık turizmi başta olmak üzere alternatif turizm türlerinin desteklenmesi. "Varış Noktası Yönetimi" kapsamında yeni projelerin hayata geçirilmesi. Dış tanıtım faaliyetlerinin etkinleştirilmesi. Yerel yönetimlerin, sivil toplum kuruluşlarının ve yerel halkın turizm ile ilgili kararlara katılması. İşgücü kalitesinin artırılması. Yüksek standartlarda hizmet sunulması. Sürdürülebilir turizm uygulamalarının geliştirilmesi. Turizmin sosyokültürel ve çevresel olumsuzluklarının azaltılması.

Genel olarak incelenen beş yıllık kalkınma planlarında turizm sektörüne yönelik belirlenen politikalardan hareketle; turizmin hızla gelişmesi için reklâm ve tanıtmanın gerekliliği vurgulanmıştır. Turizmde mevsimsel ve zamansal yoğunluğun önlenebilmesi için turizmin çeşitlendirilmesine yönelik faaliyetler teşvik edilmektedir. İlk kalkınma planından itibaren her kalkınma planında turizm personeli eğitimine işaret edilmesi dikkate değer başka bir politikadır. Kalkınma planlarının ortak ana hedefi olan dış turizmin geliştirilmesine paralel olarak, kamu çalışanlarına ile turizm personeline tatil imkânları sunulması ve yerel halkın da turizmin katma değerinden faydalanmasına yönelik olan kararlar iç turizmin de canlandırılması gerektiğini ifade etmektedir. İç ve dış turizmi canlandırmanın yanında niteliksel ve niceliksel olarak turist sayısı, geceleme süresi ve ortalama harcama miktarını gibi kalemleri artırmak turizm gelirlerini yükseltmek adına yapılan girişimleri göstermektedir. Aynı zamanda tarihi eserlerin restore edilerek korunması, turistik özelliğe sahip orman alanları, milli parklar ve kıyıların kamu yararına kullanımı da ideal uygulamalar olarak ortaya çıkmaktadır (Akça, 2016).

Türkiye'nin uluslararası rekabet ortamında imaj ve marka değerini yükseltmek için gerekli stratejilerin belirlenmesi amaciyla düzenlenen Turizm Şûralarının, ilki 20-22 Ekim 1998, ikincisi 12-14 Nisan 2002 ve üçüncüsü de 1-3 Kasım 2017 tarihlerinde Ankara'da gerçekleştirilmiştir. Düzenlenen turizm şûralarından (turizmsurasi.kulturturizm.gov.tr, 
Erişim: 02.03.2019); 1. Turizm Şûrası, Türk turizminin yapısının yurtta ve dünyada değişen ve gelişen olaylar ışığında daha ileriye götürülmesi için gerekli önlemleri saptamak ve turizm politikası ile ilgili görüşleri belirlemek amacıyla toplanmıştır. 2. Turizm Şûrası ise turizm sektörüne ivme kazandırmak ve yeni bir atılım dönemi başlatmak amacıyla toplanmıştır. Turizm sektöründe 2000'li yılların ilk yıllarında izlenmesi gereken politikalar ve atılması gereken adımlar konusunda gerçekçi ve uygulanabilir konuların belirlenmesi, tartışılması ve karara bağlanması bakımından önemli kararlar alınmış; "Geleceğimiz Türkiye" sloganıyla turizmde yeni bir atılım dönemi başlatılması amaçlanmıştır. 3. Turizm Şûrası da turizm sektörünün mevcut durumunun değerlendirilmesi ve geleceğe yönelik ulusal bir turizm politikasının oluşturulabilmesi amacıyla düzenlenmiştir. 2002 yılından itibaren yaşanan küresel, bölgesel ve yerel gelişmeler; turizm sektöründe yeni açılımları, yeni vizyonları, kalıcı ve sürdürülebilir politikaların belirlenmesini, yeni bir gelecek anlayışını önemli bir hale getirmiştir. Çevreye duyarlı, dünya gerçekleri ile uyumlu, turizm sektörünün taleplerini cevaplandırabilecek sürdürülebilir turizm politikalarının tartışılması ile turizm sektöründeki yeni eğilimleri de yakalayarak geleceğe yönelik izlenecek politikaların değerlendirilebilmesi amacı taşımaktadır. Türkiye'nin, sahip olduğu turizm potansiyelini daha da geliştirerek etkin ve doğru şekilde kullanması gerekliliği doğrultusunda, "Yeni Turizm Politikaları"nın üretilmesi amacıyla düzenlenmiştir.

\section{Yöntem}

\section{Araştırma Verileri}

Yapılan bu araştırma ile turizm şûralarında gerçekleştirilen protokol konuşmalarının kalkınma planları kapsamında değerlendirilmesi amaçlanmıştır. İncelenen protokol konuşmaları Kültür ve Turizm Bakanlığ1 (kulturturizm.gov.tr, Erişim: 02.03.2019) ile Tanitma Genel Müdürlüğü'nün (www.tanitma.gov.tr, Erişim: 02.03.2019) resmi internet sitelerinden elde edilmiştir. 1. Turizm Şûrası ve 2. Turizm Şûrası'nın protokol konuşmalarına ait sadece videolar bulunmaktadır. 1. Turizm Şûrası protokol konuşmalarına ait 57'09"'lik bir video, 2. Turizm Şûrası 
protokol konuşmalarına ait ise; 1 03'02" ve 59'16" olmak üzere iki adet video mevcuttur. Araştırma kapsamına dâhil edilen 3 adet turizm şûrasının, toplam 12 adet protokol konuşması bulunmaktadır. 1.Turizm Şûrası (20-22 Ekim 1998) Protokol Konuşmaları; Cumhurbaşkanı Süleyman Demirel, Başbakan Mesut Yılmaz ve Turizm Bakanı İbrahim Gürdal'a aittir. 2. Turizm Şûrası (12-14 Nisan 2002) Protokol Konuşmalarında ise; Cumhurbaşkanı Ahmet Necdet Sezer, Başbakan Bülent Ecevit, Devlet Bakanı ve Başbakan Yardımcısı Devlet Bahçeli, Devlet Bakanı ve Başbakan Yardımcısı Mesut Yılmaz, Turizm Bakanı Mustafa Taşar (TRT Arşiv Dairesi Başkanlığında ilgili video çekimi ham görüntü olarak saklandığı ve düzeltme yapılmadığı için ilk 11 dakikalık bölümde ses yoktur) ve Birleşmiş Milletler Dünya Turizm Örgütü (UNWTO) Genel Sekreteri bulunmaktadır. 3.Turizm Şûrası (01-03 Kasım 2017) Protokol Konuşmaları kapsamında da Cumhurbaşkanı Recep Tayyip Erdoğan ile Kültür ve Turizm Bakanı Prof. Dr. Numan Kurtulmuş'un açılış ve kapanış konuşmaları yer almaktadır.

\section{Araştırma Yöntemi}

Bu çalışmada kullanılan içerik analizi; sözel, yazıll, fotoğraflar, videolar ve ses kayıtlarını da içeren malzemelerin içerdiği anlamların yeniden yapılandırılması ya da anlamlandırılması sürecinde, malzemelerin içerdiği tüm anlamların kontrollü bir biçimde yansıtılmasıdır. Bu yaklaşımda, toplantı kayıtları, mektuplar, konuşmalar, gazete ve dergi makaleleri gibi veri kaynakları taranarak, bunlardan seçilen birimlerin niceliksel sayımı ve incelenmesi söz konusudur (Yüksel ve Yüksel, 2004: 153). $\mathrm{Bu}$ yöntem ile toplanan verileri açıllayabilecek kavramlara ve ilişkilere ulaşılmaktadır. İçerik analizinin amacı, genelde çok sayıdaki metin içeriklerinin ortak yönlerini ortaya koymaktır (Früh, 2001; Berg ve Lune, 2015). Bununla birlikte kamusal alana yönelik üretilen ve kurgulanan metinleri çözümlemeyi de amaçlamaktadır (Gökçe, 2006). Bu çerçevede içerik analizi yoluyla veriler tanımlanmaya, verilerin içinde saklı olabilecek gerçekler ortaya çıkarılmaya çalışılmaktadır. Bu temel amaçlar çerçevesinde içerik analizinin yapılışında izlenen birtakım aşamalar vardır. Bu aşamalar; verilerin kodlanması, temaların bulunması, kodların 
ve temaların düzenlenmesi ile bulguların tanımlanması ve yorumlanmasıdır (Yıldırım ve Şimşek, 2016).

Yapılan bu çalışmada da öncelikle veriler toplanmış, videolardaki konuşmalar metin haline getirilmiştir. Metin haline getirilen verilerin öncelikle araştırmacı, ardından da alanında uzman iki öğretim üyesi yardımıla incelenmesi ve kontrolü yapılmıştır. Kontrolü yapılan verilerden 1.Turizm Şûrası protokol konuşmaları için X1...X3, 2. Turizm Şûrası protokol konuşmaları için Y1...Y6 ve 3. Turizm Şûrası protokol konuşmaları için Z1...Z3 şeklinde kısaltmalar kullanılmıştır. Metin haline getirilen veriler; NVivo 12 Pro programı aracilığıyla kategorilere ayrılmıştır. Verilerin kategorilere ayrılmasında 1963-2018 yılları arasında uygulanan on adet beş yıllık kalkınma planlarında turizm ile ilgili incelenen başlıklar esas alınarak kodlar oluşturulmuştur. Oluşturulan kodlar da temalara ayrılmıştır. Veriler detaylı bir şekilde irdelenerek, çalışmanın geçerliliği ve güvenilirliğini artırmak amacıyla, protokol konuşmalarında yer alan ifadelere doğrudan yer verilerek yorumlanmıştır.

\section{Bulgular}

Yapılan analiz sonucunda, turizm şûralarında bulunan protokol konuşmalarında kalkınma planları kapsamında ele alınan konulardan toplam 10 kod ve 76 tema oluşturulmuştur. Aşağıdaki Tablo 1'de protokol konuşmalarında ele alınan kalkınma planları konularının sayısal olarak dağılımları yer almaktadır.

Tablo 1'de yer alan veriler doğrultusunda, referans sayılarına göre; protokol konuşmalarında en fazla değinilen kalkınma planı; 7. Beş Yıllık Kalkınma Planı (r=37)'dır. Bu planı sırasıyla; 10. Beş Yıllık Kalkınma Planı $(\mathrm{r}=34), 8$. Beş Yıllık Kalkınma Planı (r=27) ve 6. Beş Yıllık Kalkınma Planı $(\mathrm{r}=24)$ takip etmektedir. Protokol konuşmalarında en az değinilen konu başlıklarına sahip kalkınma planı ise; 5. Beş Yıllık Kalkınma Planı $(\mathrm{r}=7)^{\prime}$ dir. 
Tablo 1. Protokol Konuşmalarında Ele Alınan Konuların Dağılımı

\begin{tabular}{lccccccccccccc}
\hline $\begin{array}{l}\text { KALKINMA } \\
\text { PLANLARI }\end{array}$ & X1 & X2 & X3 & Y1 & Y2 & Y3 & Y4 & Y5 & Y6 & Z1 & Z2 & Z3 & $\Sigma$ \\
\hline 1. Beş Yillik & 2 & 3 & 2 & 3 & 1 & 2 & 2 & 1 & - & 1 & 1 & 2 & $\mathbf{2 0}$ \\
2. Beş Yillık & 2 & 5 & 1 & 2 & 1 & 3 & 2 & 1 & - & 1 & 1 & 2 & $\mathbf{2 1}$ \\
3. Beş Yillık & 3 & 3 & - & 1 & - & 1 & 3 & 1 & - & - & 1 & 1 & $\mathbf{1 4}$ \\
4. Beş Yillık & 2 & 1 & 4 & - & - & - & 1 & - & 1 & - & - & 1 & $\mathbf{1 0}$ \\
5. Beş Yillik & - & - & 3 & 2 & - & 1 & - & - & 1 & - & - & - & $\mathbf{7}$ \\
6. Beş Yillik & 3 & 5 & 2 & 1 & 2 & 2 & 1 & 1 & 2 & 1 & 1 & 3 & $\mathbf{2 4}$ \\
7. Beş Yillık & 3 & 5 & 3 & 5 & 1 & 5 & 3 & 3 & 2 & 2 & 2 & 3 & $\mathbf{3 7}$ \\
8. Beş Yillık & 1 & 2 & 2 & 4 & 2 & 4 & 1 & 2 & 1 & 3 & 2 & 3 & $\mathbf{2 7}$ \\
9. Beş Yillık & 1 & 2 & 2 & 4 & 1 & 3 & - & 2 & - & 1 & 2 & 3 & $\mathbf{2 1}$ \\
10.Beş Yillık & 1 & 4 & 2 & 4 & 2 & 6 & - & 3 & 1 & 2 & 5 & 4 & $\mathbf{3 4}$ \\
\hline
\end{tabular}

I. Beş Yıllık Kalkınma Planı kapsamında referans sayılarına göre en fazla tekrar sıklığına sahip konu "Uluslararası reklam firmaları aracılığıyla Türkiye'nin tanitımının yapılması" (r=7) olarak ortaya çıkmaktadır. Türkiye'nin tanıtımına öncelikli önem verildiği ve bu hususta uluslararası işletmelerden destek alınması gerektiği protokol konuşmalarında sıklıkla yer almaktadır. Genel olarak; tanıtma ve pazarlamada yeni stratejiler ve hızlı iletişim ağlarını kullanılmasının üzerinde durulmaktadır. Teknolojik gelişmelere karşın, kişilerarası iletişimin en etkin tanıtım aracı olduğunun unutulmaması gerektiğinin ve turistlerin ülkelerine döndüklerinde beğenilerini dile getirmelerinin sağlanabilmesinin üzerinde durulmuştur. Bununla birlikte doğru ve etkili tanıtımın turist sayısının artışında önemli bir etken olduğu da vurgulanmaktadır. Aynı zamanda "Turizmin gelişimini olumsuz etkileyen yasa ve hükümlerin değiştirilmesi." ( $\mathrm{r}=4$ ) başlığ 1 da üzerinde yoğunlukla durulmuş bir diğer husus olarak tespit edilmiştir. Örneğin aşağıdaki Z3 ifadesinde söz konusu durumdan şu şekilde bahsedilmektedir.

$\mathrm{Z3}=$ "... Bakanlı̆̆ın teşkilat yasası ve teşkilat yasasını ilgilendiren bazı düzenlemeler de başta olmak üzere çok fazla yasal düzenlemeyi yeniden gözden geçirmek durumundayız. Özellikle yeni bir turizm yasasına ihtiyaç olduğu da açıtır, bununla ilgili de çalışmalarımızı önümüzdeki dönemde inşallah sonuçlandıracağız."

I. Beş Yıllık Kalkınma Planı ekseninde protokol konuşmalarında sıklıkla dile getirilen "Turizm personelinin eğitilmesi." (r=3) başlığ 
altında personel eğitimine önem vermenin özellikle dünya ölçeğinde rekabet şansının artırılmasında büyük rol oynayacağı belirtilmektedir. Bununla birlikte yetişmiş nitelikli insan gücü ve kaliteli hizmet sektörü yanında hoşgörü ve konukseverlik gibi ulusal değerlerin de turizm alanında ülkeye avantaj sağlayan diğer öğeler olduğu ifade edilmektedir. Ülkeye rekabet avantajı sağlayabilecek diğer bir husus da "Bazı ülkelerde 'Turist Eğilimleri Araştırması'nın yapılması." ( $\mathrm{r}=1$ ) konusu dâhilinde aşağıdaki X2 ifadesinde yer aldığ1 şekilde ortaya çıkmaktadır.

$\mathrm{X} 2=$ “...Dı̧̧ pazarlarda değişen tüketici tercihlerini de göz önünde tutarak yeni turizm alanları ortaya çıkarmaya çalışıyoruz."

Bununla birlikte yeni turizm alanlarının ortaya çıkarılmasından bahsedilirken cazibe merkezleri üzerinde de durulmuştur. Özellikle İstanbul'un bir cazibe merkezi olduğu ve bu cazibe merkezi içerisinde yeni birtakım etkinlikler meydana getirmeye devam etmenin önemi vurgulanmıştır.

II. Beş Yıllık Kalkınma Planı kapsamında referans sayılarına göre en fazla tekrar sıklı̆̆ına sahip konu “Dış turizm gelirlerinin ve ortalama turist harcamalarının artırılması." ( $\mathrm{r}=8$ ) olarak ortaya çıkmaktadır. Turizm gelirlerinin artırılması amaciyla, yatırımın ve hizmet kalitesinin yükseltilmesi ve buna uygun stratejilerin belirlenmesinin de büyük önem taşıdığı üzerinde durulmuştur. Aşağıdaki Y3 ifadesi de ortalama turist harcamalarının artırılması yönündeki görüşü destekler niteliktedir.

Y3= “...Turizm gelirlerimiz 1980'li yillardan itibaren turist sayısina paralel olarak artmaya başlamış, fakat turizm potansiyelimizle orantılı bir gelir patlaması yaşanmamıştır. En son 2001 yılında toplam 11 milyon 596 bin turist sayısına karşı elde edilen yaklaşı 8 milyar dolarlı gelir düzeyi önemlidir ama yeterli değildir. Bu rakamlar aynı zamanda turist başına ortalama harcama miktarının düşüklüğüne de işaret etmekte ve nitelikli turist profilinin yetersizliğini ortaya koymaktadır."

Genel olarak turizmin yarattığı istihdam ve yan sektörler bakımından sağladığ1 imkânlar da düşünüldüğünde, ülke ekonomileri için vazgeçilmez ve ihmal edilemez bir sektör olduğu ifade edilmiştir. Turizmin doğrudan gelen etkilerinin yanı sıra yan sanayileri üzerindeki dolaylı rolü ve istihdam etkileriyle de ülke ekonomilerine katkıda bulunduğu ve doğrudan gelir etkileriyle birlikte yan sanayiler üzerindeki dolaylı etkileri de dikkate alındığında turizmin, ekonomik gelişme sürecindeki rolünün 
çok yönlü ve kıymetli olduğu ortaya çıkmaktadır. Özellikle tanıtım ve pazarlama konularında istenilen düzeye gelinememiş olması da dünya turizm gelirleri pastasından hak edilen payın alınmasını engelleyen temel faktörlerden biri olduğu vurgulanmıştır.

III. Beş Yıllık Kalkınma Planı kapsamında referans sayılarına göre en fazla tekrar sıklığına sahip konu "Yatırımların ve tanıtma faaliyetlerinin kitle turizmine entegre edilmesi." ( $r=6)$ olarak ortaya çıkmaktadır. Bu kapsamda özellikle dünyada Türk turizmini olumsuz yönde etkileyen en önemli faktörlerden birisinin imaj sorunu olduğu ve turizmin gelişmesinin, tıpkı sanayileşme gibi aslında milli bir mesele olduğu vurgulanmıştır. Bu konuda da sadece hükümetlerin değil aslında ülkede yaşayan herkesin görevi olduğu üzerinde durularak bilhassa yurtdışına giden veya yurtdışında sürekli yaşayan vatandaşlardan bu konuda gönüllü bir turizm elçisi gibi davranmalarının beklendiği ifade edilmiştir. Öte yandan yine referans sayılarına göre fazla tekrar sıklığına sahip olan konu "Özel sektör yatırımlarının ve özel sektör işletmeciliğinin teşvik edilmesi." ( $\mathrm{r}=3$ ) kapsamında aşağıda yer alan X1 ifadesi ile karşılaşılmıştır.

$\mathrm{X} 1=$ "...Nihayet sektör özel sektörün işidir, devletin burada yapacă̆ı şey yönlendirmedir. Yani devlet sektörü üstüne almamalıdır. O zaman sektörün gelişmesi mümkün olmaz. Sanıyorum ki Türkiye'de bugün Türk müteşebbisi Türk girişimcisi bu sektörü götürecek kadar gücü ve deneyimi ortaya koymuştur."

III. Beş Yıllık Kalkınma Planı ekseninde protokol konuşmalarında ortaya konan diğer bir husus da; hem fiziki altyapının hem de beşerî altyapının geliştirilmeye devam edilmesidir. Altyapının daha düzgün hale getirilmesi ve altyapı ihtiyaçlarının giderilmesi için gereken bütün tedbirlerin alındığı vurgulanarak turizm yatırımcılarının önündeki engellerin de kaldırılmaya çalışıldığı ifade edilmiştir.

IV. Beş Yıllık Kalkınma Planı kapsamında referans sayılarına göre en fazla tekrar sıklığına sahip olan konular "Yabancı yatırımcıların işletmecilik yapmasının özendirilmesi." (r=3) ve "Turizmin zamanda yoğunlaşmasının önlenmesi." ( $\mathrm{r}=3)$ olarak belirlenmiştir. Ülkeye yabancı yatırımcının çekilebilmesi için bazı teşviklerin olması gerektiği ifade edilmiş ve mümkün olduğu kadar, yabancı yatırımcıların Türkiye'ye çekilmesi gerektiği üzerinde durulmuştur. Ayrıca sürekli ve yoğun turist akışı sebebiyle turistik beldelerdeki, aşırı kalabalık ve altyapı yetersizliği 
ile turizm gelişiminin kültürel ve sosyal etkilerinin de denetlenme ihtiyacının ortaya çıktığı belirtilmiştir. Turizm hareketliliğinin, alışıldığı gibi sadece yaz aylarıyla sınırlı olmaktan çıkartılıp, yılın her dönemine yaymanın gerekliliği ve turizmin zamanda yoğunlaşmasının önlenmesinin üzerinde durulduğu X2 ve X3 ifadelerinde de olduğu gibi vurgulanmıştır.

$\mathrm{X} 2=$ "...Ve nihayet turizm hareketliliğini, bizde alışıldığg gibi sadece yaz aylarıla sinırlı olmaktan çıkartıp, yılın her dönemine yaymanın gayreti içindeyiz."

$\mathrm{X} 3=$ "...Kitle turizminin yanı sıra bireysel turizmin öne çıkmaya başladığ 90'lı yıllarda turizmin çeşitlendirilmesi bütün Türkiye'ye ve bütün bir yıla yayılması çalışmaları başlatılmıştır."

Ayrıca Dünya Turizm Örgütünün 2020 yılına yönelik yaptı̆̆ı projeksiyonlarda büyüme eğilimleri çerçevesinde söz konusu hedefleri yakalayabilmek için gerekli nitelikli yatak kapasitesine ulaşılması gerektiği de ifade edilmiştir.

V. Beş Yıllık Kalkınma Planı kapsamında referans sayılarına göre en fazla tekrar sıklığına sahip konu "Doğal çevre ile kültürel çevrenin korunması ve geliştirilmesi." ( $r=3$ ) olarak ortaya çıkmaktadır. Bu bağlamda kültürel mirasın ve çevrenin koruma kullanma dengesinin gözetilerek altyapı yatırımlarının devlet, üstyapı yatırımlarının ise özel sektör tarafından gerçekleştirilmesi en belirgin politika olarak ifade edilmiştir. Ülkenin tarihi zenginliklerinin ve doğal güzelliklerinin turizm açısından sürekli bir değer ifade edebilmesi için her türlü tahribattan uzak tutulması gerektiği hususu da açkça belirtilmiştir. Bu nedenle de turistik tesis ve altyapı yatırımlarında tarihi varlıkların da doğanın korunmasının da dikkate alınmasının zorunluluk olduğu Y1 ifadesinde de belirtilmiştir.

$\mathrm{Y} 1=$ "...Siklıkla yapılan imar afları, imar yetkisinin çevresel değerler göz ardı edilerek, sinırsız biçimde kullanılması, ülke turizmi yönünden önem taşıyan doğal güzelliklerin bulunduğu alanlarm yerleşime açılması, doğal ve kültürel mirasımız üzerinde büyük bir baskı ve tehdit oluşturmaktadır."

Türkiye'nin kaynaklarının, eşsizliği ve etkili ulusal turizmi destekleme politikası hem yurt içi hem yurt dışı turizm için ülkeyi çok cazip kıldığı belirtilmektedir. Bununla birlikte birçok gösterge, Türk turizminin çok başarılı bir şekilde ilerlediğini ve gelecekte de durumun farklı olmayacağını işaret ettiği ifade edilmiştir. 
VI. Beş Yıllık Kalkınma Planı kapsamında protokol konuşmalarında referans sayılarına göre en fazla tekrar sıklığına sahip konu "Alternatif turizm türleri için teşvik politikalarının geliştirilmesi." (r=8) olarak ortaya çıkmaktadır. Alternatif turizm seçenekleriyle sağlanan çeşitliliğin, sektörün de gelişmesine hız kazandırdığı Y5 ifadesinde de olduğu gibi şu şekilde belirtilmektedir:

Y5= "...Yeni ürünler istemektedir turistler. Dolayısı ile bizde bu yeni ürünleri onlara sunmak durumundayız. Ülkemizin en dışa açık ve büyümeye devam eden sektöründe bu ihtiyacı ve gelişimi göz ardı etmemiz elbette mümkün değildir."

Turizmi sadece kumsal, deniz, güneş üçgenine sıkıştıran yaklaşımlar yerine alternatif turizm alanlarını ve imkânlarını da öne çıkaran çok yönlü ve kapsamlı bir anlayış geliştirmenin gerekliliği vurgulanmaktadır. Bu çerçevede ülkemizde değişik alanlarda turizm faaliyetleri yapmak mümkün olduğu ancak bu çeşitliliğinin sağladığı zengin potansiyelin yeterince değerlendirilemediği ifade edilmektedir.

VII. Beş Yıllık Kalkınma Planı kapsamında referans sayılarına göre en fazla tekrar sıklığına sahip olan konular sırasıyla; "Yeni alternatif turizm çeşitlerinin geliştirilmesi." ( $\mathrm{r}=8$ ) ile "Tanıtma ve pazarlama faaliyetleri için özel sektörün katılımının sağlanması." ( $\mathrm{r}=7$ ) olarak belirlenmiştir. Türkiye'nin belirleyeceği uzun vadeli turizm politikası çerçevesinde topyekûn bir tanıtım ve pazarlama atağına kalkması gerektiği üzerinde durulmuştur. Tanıtma ve pazarlamada devletin her türlü desteğinin ve yardımının olacağı ama zaman zaman tanıtmada devletin çok kaynaksız kaldığı da ifade edilmiştir. Özellikle tanıtım ve pazarlama konuları, dünya turizm gelirlerinden hak edilen payın alınmasını engelleyen temel faktörlerden biri olarak belirtilmektedir. Örneğin Y4 ifadesi de tanıtım konusundaki eksikliğin varlığı yönündeki görüşü destekler niteliktedir.

$\mathrm{Y} 4=$ "...Ikincisi tanıtım olayıdır. Tanıtıma, devlet olarak ve özel sektör olarak daha fazla önem ve kaynak ayırmak zorundayız. Maalesefbiz bugün İstanbul gibi dünyanın en kıymetli markalarından birisini dahi yeterince pazarlayamıyoruz."

Bununla birlikte tanıtım sorunu ile ilgili kongre turizmi ekseninde çözüm önerisi de geliştirilmiştir. Kongre turizmi ile birlikte hem Türkiye'nin bilimsel kapasitesinin dünyaya gösterilebileceği hem de kongrelere gelen entelektüel kişilerin Türkiye'nin tanıtımı bakımından önemli bir rol üstleneceği ifade edilmiştir. 
VIII. Beş Yıllık Kalkınma Planı kapsamında referans sayılarına göre en fazla tekrar sıklığına sahip olan konu diğer önceki kalkınma planlarında da olduğu gibi "Alternatif turizm faaliyetlerinin sürdürülmesi." (r=8) olarak ortaya çıkmıştır. Farklı olarak "Dış pazarlarda Avrupa Birliği dışındaki ülkelere de yönlenmesi." ( $\mathrm{r}=4)$, "Turizmin kendi kaynağını yaratabilen bir sektör olmasının sağlanması." ( $r=3$ ) ile "Yeni alanlarda turizmin geliştirilmesi." ( $r=3$ ) başlıkları da referans sayılarına göre fazla tekrar sıklığına sahip olan konular arasında yer almaktadır. Turizmi sadece ülkenin bilinen, yurtdışında da tanınan belli bölgelerinde yapılan bir faaliyet olmaktan kurtarıp, yurt geneline de yayılma çabalarının yanında, dış pazarlarda Avrupa Birliği dişındaki ülkelere de yönlenme durumu aşağıdaki Z2 ifadesinde de belirtilmektedir.

$\mathrm{Z} 2=$ “...Türkiye şimdiye kadar gelen ülkelerden turistleri almaya, arttırarak misafir etmeye devam etme stratejisini sürdürürken, diğgr taraftan da özellikle Uzak Doğu Asya ülkelerine açılımı süratle devam ettirecektir.

Bu kapsamda mevcut pazarları geliştirmenin yanında, Çin başta olmak üzere Hindistan, Malezya, Endonezya, Japonya, Güney Kore, Güney Amerika ülkeleri gibi yeni alanlara ağırlık verilmesi gerektiği vurgulanmıştır. Bunun yanında turizmin geliştiği, bölge olarak daha çok Batı sahilleriyle Güney sahillerinde eksiklerinin tamamlaması gerektiği ardından ülkenin diğer köşelerinde yine öncelikleri mutlaka, yüksek öncelikli projelere vermek olduğu ve bu merkezlerin geliştirilmesi gerektiği üzerinde de durulmuştur.

IX. Beş Yıllık Kalkınma Planı kapsamında protokol konuşmalarında referans sayılarına göre en fazla tekrar sıklığına sahip konu "Alternatif turizm faaliyetlerinin sürdürülmesi." $(\mathrm{r}=8)$ olarak ortaya çıkmaktadır. Bununla birlikte "Yeni yörelerde turizmin geliştirilmesi." (r=3), "Yatırımların doğal, tarihi ve sosyal çevreyi korumasının sağlanması." $(\mathrm{r}=3)$ ve "Yerel yönetimlerin ve yerel halkın turizm ile ilgili kararlara katılması." (r=3) başlıkları da referans sayılarına göre yüksek tekrar sıklığına sahip olan konular arasında yer almaktadır. Özellikle devletin ve özel sektörün birlikte yürüteceği çalışmalarla altyapı eksikliklerinin giderilmesi, ülkeyi turizm alanında daha ön sıralara taşıyacak bir adım oluşturacağı ifade edilmiştir. Aynı zamanda üniversitelerin, sivil toplum örgütlerinin, turizm sektör temsilcilerinin ve turizmin önemini bilen herkesin aslında hep beraber olduğu ve sürekli desteklendiği vurgulanmıştır. Bu 
desteğin toplum geneline yayılması ve sağlaması hedeflenerek, her vatandaşı bu seferberliğe dâhil etmek ve toplum genelinde bir turizm duyarlılığı yerleşmesinin amaçlandığ 1 Y1 ifadesinde de olduğu gibi belirtilmiştir.

$\mathrm{Y} 1=$ "...Şûra'da ortaklaşa alınacak kararlar ortaya çıkacak, öngörüler, turizm sektörünün geleceği için bir yol haritası niteliğini taşımaktadır. Bunların başarıyla gerçekleştirmesi konusunda devletin yanı sıra sektörün tüm taraflarına görev düştüğ̈̈ne inanıyorum. Şûra'nın, sektörün tüm taraflarmı bir araya getirerek, turizm sektöründe büyük atılımlar gerçekleştirilebilmesi yolunda yeni bir başlangıç oluşturmasını umut ediyorum."

Ayrıca bütün kamu kurum ve kuruluşlarının özel sektörle yerel halkla ve sivil toplum kuruluşlarıyla yan yana olup ortak hareket etmeleri ve tek bir hedef etrafında hareket etmeleri gerekliliği de ifade edilmiştir.

X. Beş Yıllık Kalkınma Planı kapsamında protokol konuşmalarında referans sayılarına göre en fazla tekrar sıklığına sahip konu "Turizmde marka haline gelinmesinin sağlanması." ( $\mathrm{r}=7$ ) olarak ortaya çıkmaktadır. $\mathrm{Bu}$ hedefe ulaşabilmenin birinci koşulunu, dünyadaki gelişmeleri yakından izleyen etkili tanıtma stratejilerinin yaşama geçirilebilmesi oluşturmakta olduğu ifade edilmiştir. Aynı zamanda bu anlamda bir gelecek planlaması yapma durumunda olunduğunu ve bunun için geleceğin turist profilinin taleplerini ve geleceğin turizm anlayışını bugünden doğru tespit etmek ve gereken yapılanmaları da gerçekleştirmek zorunda olunduğu belirtilmiştir. Örneğin aşağıdaki Z3 ifadesinde benzer söylemler mevcuttur.

Y5= "Her sektörün yapmasi gereken marka oluşturma imaj oluşturma ve tanıtma işlerini dışımızdaki her sektöre model olacak bir yapılanma ve çalışmayla gerçekleştiriyoruz..."

Ayrıca sürdürülebilir turizm uygulamalarının geliştirilmesi konusunda da özellikle turizm bilincinin çevre bilinciyle birleştirmiş, yeni kuşakların turizmin bugün dünyada taşıdığı önemin bilincinde olan yeni kuşakların yetiştirilmesinin önemi vurgulanmıştır. Türkiye'nin turizm alanında uzun vadeli düşünerek hareket etmesi ve sahip olduğu değerleri yok etmeden kalkınma çabalarını sürdürmesinin önem taşıdığı belirtilmiştir. Özellikle Turizm Şûra'larını fırsat bilerek, doğal kültürel ve tarihsel zenginliklerin korunarak sonraki nesillere aktarılabilmesinin ülkenin geleceği yönünden de büyük önem taşıdı̆̆ını ifade edilmiştir. Bununla 
birlikte turizm alanında yetişmiş nitelikli işgücünün de konuya gösterdikleri duyarlığın artması ve akılcı politikaların izlenmesiyle Türk turizminin çok daha iyi yerlere mutlaka ulaşacağı vurgulanmıştır.

\section{Sonuç ve Değerlendirme}

Yapılan bu çalışmayla bugüne kadar düzenlenmiş olan Turizm Şûralarındaki protokol konuşmaları, 1963-2018 yılları arasında yayımlanan Türkiye'nin beş yıllık kalkınma planları kapsamında incelenmiştir. Türkiye'de turizm ilk kez 1960'lı yıllarda bir sektör olarak hükümetin kalkınma programına girmiş, turizmin bir politika ekseninde geliştirilmesi esas alınmıştır. Turizmin kamu yönetimi içinde Bakanlık olarak örgütlenmesi ise 1963 yılında gerçekleştirilmiştir. 1982 yılında yürürlüğe giren 2634 sayılı Turizmi Teşvik Kanunu, turizmin gelişmesinde belirleyici rol oynamıştır. Bu yasanın sağladığı imkân ile turizm alan ve merkezlerinin belirlenmesi, bu alan ve merkezlerde bulunan kamu arazilerinin yatırımcıya tahsisi, 1982 sonrasındaki hızlı yatırım genişlemesinin en önemli etkenlerinden biri olmuştur. Kitle turizminin yanı sıra bireysel turizmin öne çıkmaya başladığı 90'lı yıllarda turizmin çeşitlendirilmesi ile bütün Türkiye'ye ve bütün bir yıla yayılması çalışmaları başlatılmıştır.

İncelenen protokol konuşmalarında genel olarak yapısı itibariyle; turizm sektörünün sorunlarının tartışılacağı ve ilgili tüm kesimlerin katılımıyla bu sorunlara uygun çözümlerin üretileceği bir platform olan söz konusu şûraların toplanması turizm sektörü açısından son derece olumlu bir gelişme olarak nitelendirilmektedir. Turizminin küresel ölçekte değişen koşullara uyum sağlayabilmesi ve daha ileriye gidebilmesi için alınması gereken tedbirlerin bu platformlarda tartışılması, olgunlaştırılması ortaya konulması da gerçekleşmektedir. Bununla birlikte turizm politikalarına ilişkin esaslar da söz konusu şûralarda dile getirilmesi ve ülkenin yeni turizm stratejileri belirlemesi bakımından önem arz etmektedir.

Ülke ekonomisi yönünden büyük önem taşıyan turizm Türkiye'nin geleceği olarak ifade edilmektedir. Bu yönde hazırlanan ve uygulamaya konulan politikaların amacına ulaşması, ekonominin canlanması için olumlu bir ortam yaratacaktır. Ülkenin turizm alanında daha iyi bir 
düzeye gelmesi temel hedef olarak gösterilmektedir ve bu temel hedefe ulaşabilmenin koşulunu, dünyadaki gelişmeleri yakından izleyen etkili tanıtma stratejilerinin yaşama geçirilebilmesi oluşturmaktadır. Turizmin geliştirilmesi ve daha ileriye götürülmesi Türkiye'nin en öncelikli sorunlarından birisi olduğu işaret edilmekte ve toplanan şûraların da aslında bu sorunu gidermeye yönelik olduğu belirtilmektedir. Bunun yanında şûralara katılan; ülkede turizm alanında bilgi sahibi, deneyim sahibi katılımcı olması ve turizmin daha güzelleştirilmesi, daha ileriye götürülmesi için her alanda alınabilecek tedbirleri daha iyi ortaya koyabilmeleri de Türkiye'deki turizm anlamında önemli gelişmelerinden biri olarak ifade edilmektedir.

Turizm sektörü, ulusları kaynaştıran, kültürlerarası iletişim ile insanların birbirini tanımasına ve etkileşimde bulunmasına olanak sağlayan ve ülkelerarası ilişkilerin geliştirilmesine katkıda bulunan ve bu yönüyle evrensel barışa hizmet eden çok önemli bir araçtır. Bu anlamda turizmin modern insanın vazgeçilmez bir ihtiyacı haline geldiği ve iyi bir tatil için insanların imkânları ölçüsünde her türlü mesafeyi, meşakkati ve maliyeti göze alabildikleri belirtilmektedir. Ancak bu kapsamda seyahat edenlerin ortak beklentileri ve bazı ön koşulları bulunmaktadır. Tatilde kendisini her bakımdan güvende hissetmek hijyen kurallarına uygun bir ortam bulabilmek, ulaşım ve iletişim sorunu yaşamamak gibi hususlar, turistlerin tercihlerini etkileyen en önemli faktörler olarak ortaya çıkmaktadır. Bunun yanında Türk turizmini olumsuz yönde etkileyen faktörlerden birisinin de imaj sorunu olduğu ifade edilmektedir. Olumsuz imaj oluşturan unsurlar olarak da insan hakları ihlalleri iddiaları, terör sorunu ve insan sağlığ1 ve güvenliğini olumsuz etkileyebilecek durumlar gösterilmektedir. Bunun yanında insan sağlığı ve güvenliğinin tehlikede olmadığı, insana saygıll, çevreye duyarlı, evrensel değerleri benimsemiş bireylerden oluşan toplumlarla karşılaşmak, turistin değişmez beklentisi durumuna gelmektedir. Bu nedenle, turistin beklentisine ve mutluluğuna yanit verecek uygulamalara öncelik tanıyan, onların olaylara, çevreye ve evrensel değerlere duyarlılığını dikkate alan politikaların saptanması, turizmin geliştirilmesi yolunda temel bir zorunluluk olarak ifade edilmektedir.

Son olarak ülkenin yanlış tanınmasına yol açacak uygulamalardan özenle kaçınılması gerektiği vurgulanmaktadır. Protokol konuşmalarında Türkiye'nin yapacağı en etkin tanıtımın, turizmi geliştirmek olduğu 
yoğunlukla ifade edilmektedir. Bu bağlamda daha iyi, daha etkin bir şekilde hedefe ulaşabilmek için kongre turizmine özel önem verilmesi gerektiği belirtilmektedir. Kongre turizmiyle Türkiye'ye gelecek olan insanların eğitim düzeylerinin ve etki alanlarının yüksek olmasıyla tanıtımda olumlu sonuçlar elde edileceğini düşündürmektedir. Bununla birlikte kongre merkezleri üzerinde de hassasiyetle durulmaktadır. Türkiye'de birçok yerin cazibe merkez olduğu ve bu cazibe merkezleri içerisinde yeni birtakım etkinlikler meydana getirilmesi gerektiği ve eksik olan tesislerin de yapılması gerektiği belirtilmektedir. Kongre turizminin yanında dünya turizm konseptinin dört yönlü bir anlayışa doğru yöneldiği ortaya konmaktadır. Artık tek başına deniz turizmi, tek başına doğa turizmi, tek başına kültürel turizm ve tek başına otantik kültür unsurlarının yeterli olmadığı ve bütün bunları birleştiren bir turizm anlayışının dünyada ön plana çıtı̆̆ı vurgulanmıştır. 


\title{
EXTENDED ABSTRACT
}

\section{An Evaluation of The Protocol Speeches Given at The Tourism Councils in The Scope of Development Plans}

\author{
Gencay Saatc1 \\ Çanakkale Onsekiz Mart University
}

The State Planning Organization (DPT), Five Year Development Plan prepared by Turkey's current economic, social and cultural fields, the main policy documents outlining the growth will be realized in the long term. Since 1963, ten development plans have been prepared to cover the year 2018, and the desired objectives and the desired structure have been discussed (Tüzünkan, 2015; Akça, Şahan and Tural, 2017). Considering the tourism phenomenon in these five-year development plans; Initially, tourism was seen as an economic activity in development plans. In the short term, it is aimed to increase the tourism movements and economic benefits, and to take necessary measures to ensure the rapid development of the tourism industry. In the first period, a large proportion of the mass tourism oriented travels are targeted; in order to provide the geographical distribution of demand in the subsequent tourism plans, to decrease the seasonality, to diversify the touristic product on the axis of alternative tourism varieties with higher added value and to benefit from the tourism opportunities in every season. However, smaller tourism establishments where local people can participate in investments were encouraged (Dinçer \& Çetin, 2015; Keleş \& Akbaş, 2016). The importance of tourism in economic development has been appreciated by every government and this perspective has also been reflected on the five-year development plans prepared by the State Planning Organization (Ünlüönen, Tayfun and K1lıçlar, 2007). 
Based on the policies determined for the tourism sector in the five-year development plans examined in general; the need for advertising and promotion for the rapid development of tourism is emphasized. In order to prevent seasonal and temporal intensity in tourism, activities aiming to diversify tourism are encouraged. It is noteworthy that, in the first development plan, tourism personnel training is indicated in each development plan. Parallel to the development of external tourism, which is the common goal of development plans, it is stated that domestic tourism should be provided to public employees and tourism personnel and the decisions of local people to benefit from the added value of tourism should be stimulated by domestic tourism. In addition to stimulating domestic and foreign tourism, qualitatively and quantitatively, increasing the number of tourists such as the number of tourists, overnight stay and average spending amount shows the initiatives made to increase tourism revenues. At the same time, restoration and preservation of historical monuments, forest areas with touristic features, national parks and use of the coasts in public interest also appear as ideal practices (Akça, 2016).

The Tourism Council, which has an important place in the history of Turkish tourism, is one of the most important platforms that brings together the parties of the sector in terms of comprehensively addressing the problems in the tourism sector, approaching the problems of tourism with a long-term understanding, developing tourism, creating prospective, lasting policies and taking decisive steps feature.

\section{Methodology}

Content analysis used in this study; verbal, written, photographs, video and audio recordings, including the meaning of the materials contained in the process of restructuring or meaning, all the meanings of materials are reflected in a controlled way. In this approach, data sources such as meeting records, letters, speeches, newspaper and magazine articles are searched, and quantitative counting and examination of the selected units is in question (Yüksel and Yüksel, 2004: 153). The concepts and relationships that can explain the data collected by this method are reached. The aim of content analysis is to reveal common aspects of a large number of text contents (Früh, 2001; Berg and Lune, 2015). However, it aims to 
analyze produced and constructed texts for public space (Gökçe, 2006). In this context, data are tried to be defined through content analysis and facts are tried to be revealed. Within the framework of these basic objectives, there are some stages followed in the content analysis. These stages; coding of the data, finding the themes, editing of codes and themes, identifying and interpreting the findings (Yıldırım and Şimşek, 2016).

In this study, the data were collected first and the speeches in the videos were made into text. The data, which was transformed into text, was firstly examined by the researcher and then by the help of two faculty members. From the control data, the abbreviations Z1 ... Z3 are used for the protocol conversations of the $X 1, X 3,2$. Tourism Council protocol conversations for the Y1 ... Y6 and 3. Tourism Council protocol conversations. Textual data; NVivo 12 Pro is divided into categories through the program. Codes were categorized in ten five-year development plans implemented between the years 1963-2018, based on the titles examined in relation to tourism. Created codes are also divided into themes. In order to increase the validity and reliability of the study, the data were directly interpreted and interpreted.

\section{Results}

As a result of the analysis, a total of 10 codes and 76 themes were created from the topics discussed in the scope of development plans in the protocol speeches in the tourism cities. According to reference numbers; the most discussed development plan in protocol speeches; The 7th Five-Year Development Plan ( $\mathrm{r}=37$ ) is 7 .. This plan is respectively; The 10th FiveYear Development Plan $(r=34)$ is followed by the 8th Five-Year Development Plan $(r=27)$ and the 6th Five-Year Development Plan $(r=24)$. Development plan which has the least mentioned topics in the protocol speeches is; 5. Five-Year Development Plan ( $r=7)$.

\section{Conclusion and Evaluation}

In terms of the overall structure of the protocol speeches examined; The collection of these cities, which is a platform where the problems of the tourism sector will be discussed and the appropriate solutions for these 
problems will be produced with the participation of all concerned groups, is considered as a very positive development for the tourism sector. It is also realized that the measures to be taken in order to adapt to the changing conditions of tourism on a global scale and to move forward in these platforms are discussed and matured. In addition, the principles regarding tourism policies are important in terms of voicing these policies and determining new tourism strategies of the country.

Which is of great importance to the tourism economy of the country is called Turkey's future. The policies prepared and implemented in this direction will create a positive environment for the revival of the economy. The goal of achieving a better level of tourism in the country is shown as the main objective and the aim of achieving this goal is to implement effective promotion strategies that closely follow developments in the world. and further continuation of the tourism development and demonstration in Turkey as one of the priority issues and the collection of Suraya also pointed to the fact that the solution to this problem. You can also join cities; information in the field of tourism in the country, more participatory and tourism flourish, flourish more in all areas of better measures can be taken to show that better measures can be taken to show tourism in Turkey.

\section{Kaynakça / References}

Akça, Y. (2016). Türkiye'nin kalkınma planlarında turizm politikası. International Conference on Eurasian Economies, 29-31 Ağustos, Kaposvar.

Akça, Y., Şahan, G. ve Tural, A. (2017). Türkiye'nin kalkınma planlarında eğitim politikalarının değerlendirilmesi. International Journal of Cultural and Social Studies, 3(Special Isuue), 394-403.

Barutçugil, İ. S. (1986). Turizm ekonomisi ve turizmin Türk ekonomisindeki yeri. İstanbul: Beta Yayıncilı.

Berg, B. L. ve Lune, H. (2015). Sosyal bilimlerde nitel araştırma yöntemleri. (Ed. Hasan Aydın). Konya: Eğitim Yayınları.

Büyükşalvarcı, A., Şapcılar, M. C. ve Bayrakcı, S. (2016). Kalkınma planları kapsaminda turizm endüstrisinin değerlendirilmesi. Selçuk $\ddot{U} n-$ iversitesi Sosyal ve Teknik Araştırmalar Dergisi, 11, 186-201. 
Çeken, H. (2003). Küreselleşme, yabancı sermaye ve Türkiye turizmi. İstanbul: Değişim Yayıncılık.

Dinçer, M. Z. ve Cetin, G. (2015). Kalkınma planlarında turizm. İç. D. Küçükaltan, H. Çeken \& Ş. O. Mercan (Ed.) Değgişik perspektifleriyle turizm politikası ve planlaması. Ankara: Detay Yayıncılık.

Früh, W. (2001). Inhaltsanalyse. theorie und Praxis. Konstanz: UVK Verlagsgesellschaft.

Gökçe, O. (2006). İ̧̧erik analizi kuramsal ve pratik bilgiler. Ankara: Siyasal Kitabevi.

http://turizmsurasi.kulturturizm.gov.tr/TR-169845/sura-hakkinda.html, Erişim: 02.03.2019.

http://turizmsurasi.kulturturizm.gov.tr/TR-196964/protokol-konusmalari.html, Erişim: 02.03.2019.

http://www.sbb.gov.tr/kalkinma-planlari/, Erişim Tarihi: 26.03.2019. http://www.tanitma.gov.tr/TR-191456/turizm-tarihinde-bir-kesit.html, Erişim: 02.03.2019.

Karslı, H. (1997). Türkiye'de planl dönemde turizm yatırımlar ve uygulanan politikalar. Yayımlanmamış yüksek lisans tezi, İzmir: Dokuz Eylül Üniversitesi.

Keleş, Y. ve Akbaş, Y. Z. (2016). Yozgat ilinin termal turizm potansiyelinin 2023 turizm vizyonu kapsaminda incelenmesi. I. Uluslararası Bozok Sempozyumu, 5-7 Mayis, Yozgat.

Kozak, N., Akoğlan Kozak, M. ve Kozak, M. (2009). Genel turizm: ilkelerkavramlar. Ankara: Detay Yayıncilık.

Olalı, H. ve Timur, A. (1988). Turizm ekonomisi. İzmir: Ofis Matbaası.

Soyak, M. (2013). Uluslararası turizmde son eğilimler ve Türkiye'de turizm politikalarının evrimi. Marmara Sosyal Araştırmalar Dergisi, 4, $1-18$.

Tüzünkan, D. (2015). Türkiye'de uygulanan beş ylllık kalkınma planlarının istihdam politikaları açısından değerlendirilmesi. Beykent Üniversitesi Sosyal Bilimler Dergisi, 8(2), 90-117.

Uçar, M., Çeken, H. ve Ökten, Ş. (2010). Kırsal turizm ve kırsal kalkınma (fethiye örneği). Ankara: Detay Yayıncılık.

Usta, Ö. (2014). Turizm: genel ve yapısal yaklaşım. Ankara: Detay Yayıncılık. Ünlüönen, K., Tayfun, A. ve Kılıçlar, A. (2007). Turizm ekonomisi. Ankara: Nobel Yayıncilık. 
Yemen, A. (2015). Kalkınma planlarında büyükşehirlerin mevcut durum analizi. Uluslararası Sosyal Araştırmalar Dergisi, 8 (37), 999-1023.

Yıldırım, A. ve Şimşek, H. (2016). Sosyal bilimlerde nitel araştırma yöntemleri. Ankara: Seçkin Yayıncılık.

Yüksel, A. ve Yüksel F. (2004). Turizmde bilimsel araştırma yöntemleri. Ankara: Turhan Kitabevi.

\section{Kaynakça Bilgisi / Citation Information}

Saatcı, G. (2019). Turizm şûraları protokol konuşmalarının kalkınma planları kapsamında değerlendirilmesi. OPUS-Uluslararası Toplum Araştırmaları Dergisi, 11(18), 2309-2336. DOI: 10.26466/opus.554732 